\title{
Small Mammal Habitat Use within Restored Riparian Habitats Adjacent to Channelized Streams in Mississippi
}

\author{
Peter C. Smiley Jr. ${ }^{1^{*}}$, Charles M. Cooper ${ }^{2}$ \\ ${ }^{1}$ USDA-ARS Soil Drainage Research Unit, Columbus, Ohio, USA; ${ }^{2}$ USDA-ARS National Sedimentation Laboratory, Oxford, Mis- \\ sissippi, USA. \\ Email: "rocky.smiley@ars.usda.gov
}

Received August 24 $4^{\text {th }}, 2013$; revised September 27 $7^{\text {th }}, 2013$; accepted October $25^{\text {th }}, 2013$

This article is a US Government work and is in the public domain in the USA. This is an open access article distributed under the Creative Commons Attribution License, which permits unrestricted use, distribution, and reproduction in any medium, provided the original work is properly cited.

\begin{abstract}
Riparian zones of channelized agricultural streams in northwestern Mississippi typically consist of narrow vegetative corridors low in habitat diversity and lacking riparian wetlands. Land clearing practices and stream channelization have led to the development of gully erosion and further fragmentation of these degraded riparian zones. Currently, installation of a gully erosion control structure (drop pipe) at the riparian zone-agricultural field interface leads to the incidental establishment of four riparian habitat types that differ in habitat area, vegetative structure, and pool size. Small mammals were sampled within four sites of each habitat type from June 1994 to July 1995. Small mammal diversity, abundance, and hispid cotton rat (Sigmodon hispidus) weight were the least within smallest Type I habitats with the least vegetative structural diversity and were the greatest within the larger Type II, III, or IV habitats having greater vegetative structural diversity and pool size. Small mammal diversity and abundance were the least in the summer 1994, increased in the fall 1994, and then declined later in our study. Hispid cotton rat abundance was the least in summer 1994, winter 1994, and spring 1995 and was the greatest in fall 1994 and summer 1995. Our results suggest that modifying the drop pipe installation design to facilitate the development of larger riparian habitats with greater vegetative structural diversity will provide the greatest benefits for small mammals.
\end{abstract}

Keywords: Gully Erosion; Channelization; Channel Incision; Erosion Control; Small Mammals

\section{Introduction}

Within the last 200 years, $>80 \%$ of riparian zones in North America and Europe have been destroyed and human induced modification of the remaining habitat continues [1]. Intact riparian zones are critical landscape features required for the maintenance of biodiversity [2]. Riparian zones exhibit high levels of plant and animal diversity, and may facilitate ecological and genetic exchange by serving as connectivity areas with other ecosystems [3]. When upland forest or grassland habitat bordering streams is cleared for agriculture, the remaining riparian zones may increase in significance as habitat for small mammals [4]. Riparian zones that differ in vegetative structure and species composition from adjacent upland habitats have greater diversity and abundance of small mammals [5-7].

Riparian zones adjacent to channelized agricultural

"Corresponding author. streams in northwestern Mississippi consist of narrow vegetative corridors low in habitat diversity and lacking riparian wetlands. Agriculture and stream channelization have contributed to the degradation of these riparian zones since the 1830s [8]. The initial reduction of riparian zone width occurred as land adjacent to these streams was cleared and developed for agriculture. Federal channelization projects conducted between 1930 and 1960 initiated severe channel incision that resulted in the destabilization of entire watersheds [9]. Channel incision severs the typical floodplain-stream linkage and frequently results in gully erosion that rapidly migrates perpendicular to the stream through the riparian zone and into the agricultural field. Agricultural land in northwest Mississippi has been the location of some of the most active gully systems in the United States [10,11]. Gully erosion is the most severe form of soil erosion and can result in soil loss rates between 0.1 to $65 \mathrm{t} \cdot \mathrm{ha}^{-1} \cdot$ year $^{-1}$ [12]. Fur- 
thermore, the creation of gaps caused by the loss of soil and riparian vegetation as a result of gully erosion leads to fragmentation of the riparian zones. Riparian habitat degradation resulting from channelization typically decreases small mammal diversity and abundance [13-15] and alters species composition [16]. The high frequency of gully erosion adjacent to channelized agricultural streams and the severity of the resulting erosion have resulted in the installation of thousands of drop pipes in northwest Mississippi [9,17].

Installation of drop pipes is often supported on a costshare basis by the USDA Natural Resources Conservation Service, US Army Corps of Engineers, and other action agencies in the United States [18]. The drop pipe structure consists of an earthen dam placed across eroding gullies with an embedded L-shaped metal pipe that transports runoff to the stream (Figure 1). Drop pipe installation halts gully erosion and allows for the incidental development of riparian habitat that reconnects riparian zones fragmented by gully erosion $[19,20]$. Previous assessments have documented differences in fish, amphibian, reptile, bird communities, and avian nest predators among riparian habitats established by drop pipes [17,21-24]. Previous findings also confirmed that forested riparian wetlands had greater vertebrate species richness (i.e., combined species richness of all vertebrate classes) than riparian habitats impacted by gully erosion and terrestrial riparian habitats created by drop pipe installation $[19,25]$. Differences in small mammal communities and populations among riparian habitats established by drop pipe installation have not been examined.

Previous studies $[15,26]$ have evaluated small mammal responses to streamside management zones and stream restoration within forested watersheds in the southeastern United States. However, information on small mammal which responses to riparian habitat restoration within

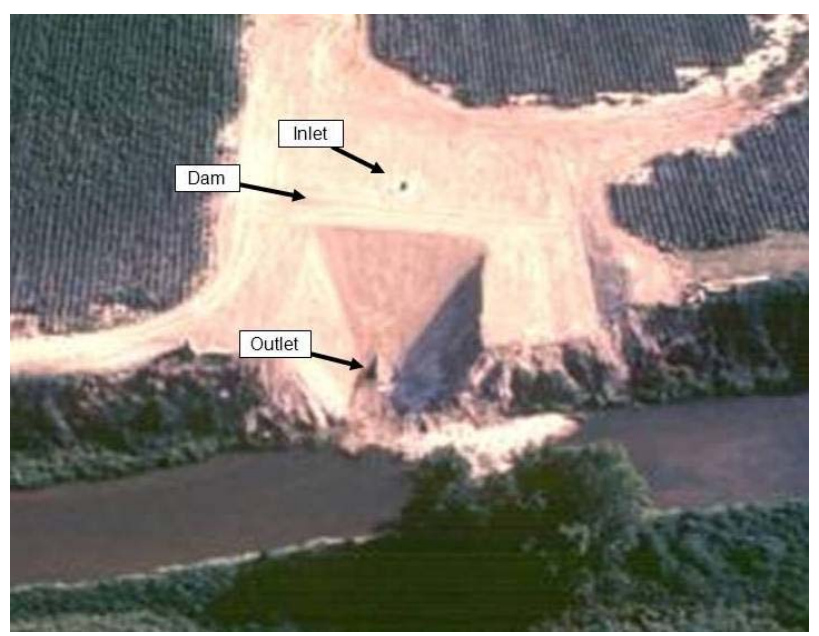

Figure 1. Aerial photograph of newly installed drop pipe structure. agricultural watersheds in this region is lacking. We sampled small mammals over a one-year period from four riparian habitat types established as a result of drop pipe installation in northwestern Mississippi to examine small mammal habitat use within these restored riparian habitats. Specifically, our research questions were: 1) Does small mammal community structure differ among habitat type and season?; and 2) Does the abundance, weight, number of recaptures, and movement patterns of hispid cotton rats (Sigmodon hispidus) differ among habitat type and season?

\section{Materials and Methods}

\subsection{Habitat Classification and Description}

A pre-study survey of 180 drop pipe sites within the Yazoo River watershed indicated that restored riparian habitats fit one of four discrete types on the basis of habitat area, pool volume, and vegetative structure (Table 1). Subsequent plant censuses and total station surveys [17] supported our initial habitat classification. Type I habitats were the smallest riparian patches and were composed mostly of herbaceous vegetation (Table 1). The four dominant plant species within Type I habitats were bermuda grass (Cynodon dactylon), goldenrod (Solidago spp.), paspalum grass (Paspalum spp.), and panic grass (Panicum spp.). Type II habitats were larger riparian patches than Type I habitats (Table 1) and were composed of herbaceous vegetation mixed with shrubs and saplings. The four dominant plant species within Type II habitats were Japanese honeysuckle (Lonicera japonica), goldenrod, white ash (Fraxinus americana), and blackberry (Rubus argutus). Type III habitats were riparian patches larger than Type II habitats (Table 1) and characterized by the presence of an ephemeral pool surrounded by a ring of woody vegetation. The four most frequently occurring plant species were black willow (Salix nigra), bermuda grass, ragweed (Ambrosia artemisiifolia), and kudzu ( $\mathrm{Pu}$ eraria lobata). Type IV habitats were characterized by having the greatest habitat area, permanent pools, greatest plant species richness (Table 1), and an input channel extending into the adjacent field. Vegetation within Type IV habitats consisted of woody and herbaceous vegetation, and the four most frequently occurring plant species were blackberry, goldenrod, partridge pea (Cassia fasiculata), and bermuda grass. The amount of woody vegetation within a site varied more among Type IV habitats than Type III habitats. Type IV habitats ranged from sites composed of predominantly herbaceous vegetation with a few mature trees $>2 \mathrm{~m}$ tall to sites that contained pools and input channels surrounded by mature trees $>2 \mathrm{~m}$ tall. Type IV habitats contained the largest trees and common woody species included black willow, American elm (Ulmus 
Table 1. Mean total habitat area $\left(\mathrm{m}^{2}\right)$, mean maximum pool volume $\left(\mathrm{m}^{3}\right)$, mean plant species richness (plant richness), and mean vertical structure of woody vegetation index within four restored riparian habitat types in northwestern Mississippi, June 1994 to July 1995.

\begin{tabular}{ccccc}
\hline Habitat Type & Habitat Area & Pool Volume & Plant Richness & Vertical Structure Index $^{\mathrm{b}}$ \\
\hline Type I $(\mathrm{n}=4)$ & 600 & 15 & 22 & 0.01 \\
Type II $(\mathrm{n}=4)$ & 1000 & 41 & 22 & 0.21 \\
Type III $(\mathrm{n}=4)$ & 1300 & 426 & 26 & 0.30 \\
Type IV $(\mathrm{n}=4)$ & 3700 & 1343 & 46 & 0.20 \\
\hline
\end{tabular}

${ }^{\mathrm{a}}$ See [17] for description of sampling methods for all response variables; ${ }^{\mathrm{b}}$ Index of vertical structure indicates dominance of woody vegetation greater than 1.8 $\mathrm{m}$ tall and ranges in scores from 0 (site lacking woody vegetation $>1.8 \mathrm{~m}$ tall) to 1 (site dominated by woody vegetation $>1.8 \mathrm{~m}$ tall) [17].

americana), American sycamore (Platanus occidentalis), and sweet gum (Liquidambar styraciflua).

The pre-study survey of 180 drop pipe sites also found that Type I habitats occurred most frequently (61\%), followed in abundance by Type III (21\%), Type II (11\%), and Type IV (7\%) habitats [9]. We selected four sites of each habitat type within the Long and Hotophia Creek watersheds in Panola County, Mississippi (lat $34^{\circ} 9^{\prime}$ to $34^{\circ} 33 \mathrm{~N}$, long $89^{\circ} 43^{\prime}$ to $90^{\circ} 11^{\prime} \mathrm{W}$ ) as study sites (total 16 sites). Both watersheds were predominantly agricultural watersheds primarily devoted to cotton (Gossypium hirsutum) production. All study sites were adjacent to channelized agricultural streams and agricultural fields. We attempted to control for the potential influence of land use by choosing sites that were adjacent to cotton fields. Fifteen sites were adjacent to cotton fields, but logistical matters required us to select one site adjacent to a corn (Zea mays) field.

\subsection{Small Mammal Trapping}

Small mammals were sampled from 28 June 1994 to 20 July 1995 with sherman folding live traps $(7.6 \mathrm{~cm}$ wide by $8.9 \mathrm{~cm}$ tall by $22.9 \mathrm{~cm}$ long) and pitfall traps $(19 \mathrm{~L}$ buckets that are $34.9 \mathrm{~cm}$ tall and $28.6 \mathrm{~cm}$ in diameter) buried flush with the ground. The combined use of live traps and pitfall traps enabled us to sample the entire small mammal community more effectively. Pools within Type III and Type IV habitats prevented the use of the standard grid trapping array. Therefore, we established a trapping transect along the perimeter of each Type I, II, III, and IV site. The trapping transect encircled the entire site of Type I, II, and III sites. The large size of Type IV sites made surrounding the entire site impractical and the trapping transect was placed so it encircled the large pools within these sites. Placement of live traps and pitfall traps were alternated along the trapping transect and each trap was located $5 \mathrm{~m}$ apart. All traps were at least 1 $\mathrm{m}$ from the edge of all habitat types and the adjacent agricultural field. The total number of traps within a site varied, but the number of traps per transect length required to encircle the site (Type I, II, III) or pool (Type IV) was similar. Wood covers were placed above pitfall traps and aluminum covers were placed over live traps to reduce trap mortality. Pitfall traps were unbaited and live traps were baited with a combination of peanut butter, rolled oats, and mixed seed the first trapping period of summer 1994. Rolled oats were used as bait for subsequent trapping periods because of problems with ants.

Trapping periods were summer 1994 (28 June to 1 July 1994; 18 July to 27 July 1994), fall 1994 (8 November to 16 November 1994), winter 1995 (21 February to 28 February 1995), spring 1995 (17 April to 26 April 1995), and summer 1995 (13 July to 20 July 1995). Trapping was conducted for 7 to 9 nights during each season within all sites. Traps were checked daily during each season and were closed between seasons. All animals captured were identified to species and released. Cotton rats were also weighed with spring scales and individually marked with ear tags (\#1, National Band and Tag Co.).

\subsection{Data Analyses}

We calculated species richness (the number of species captured), evenness (the reciprocal of the Simpson's Index divided by species richness) [27], Shannon Diversity Index [28], and abundance (the number of captures) from every site during each season. Our use of two sampling methods with different capture efficiencies and the variability in sampling effort among habitat types and seasons (Table 2) required the use of an index to standardize our sampling effort. First, the sampling effort (i.e., number of live trap nights and number of pit fall trap nights) within all sites and sampling periods for each sampling method was ranked. The sampling effort index is then calculated by summing the rank sampling effort of all sampling methods used in each site during each season [24]. We then standardized species richness and abundance values by dividing the values of these variables by the sampling effort index.

We calculated cotton rat abundance (\# of individuals captured/sampling effort index), percent of juveniles (\# of individuals $<100 \mathrm{gm}$ in weight/total \# of individuals) captured, mean cotton rat weight, and mean number of 
Table 2. Mean number of trap nights for live traps (LT) and pitfall traps (PF) within four restored riparian habitat types in northwestern Mississippi during each season from June 1994 to July 1995.

\begin{tabular}{|c|c|c|c|c|c|c|c|c|}
\hline & \multicolumn{2}{|c|}{ Type I } & \multicolumn{2}{|c|}{ Type II } & \multicolumn{2}{|c|}{ Type III } & \multicolumn{2}{|c|}{ Type IV } \\
\hline & $L T$ & $P F$ & $L T$ & $P F$ & $L T$ & $P F$ & $L T$ & $P F$ \\
\hline Summer 1994 & 22 & 24 & 66 & 68 & 96 & 94 & 105 & 110 \\
\hline Fall 1994 & 22 & 24 & 82 & 84 & 102 & 100 & 120 & 126 \\
\hline Winter 1995 & 19 & 21 & 72 & 74 & 89 & 88 & 105 & 110 \\
\hline Spring 1995 & 25 & 27 & 92 & 95 & 115 & 113 & 135 & 142 \\
\hline Summer 1995 & 19 & 21 & 72 & 74 & 89 & 88 & 105 & 110 \\
\hline
\end{tabular}

recaptures from each site during each season. We also calculated the average distance moved by an individual cotton rat (AVDI) with at least one recapture within each site. AVDI is the sum of all distances moved by an individual cotton rat divided by the number of days elapsed between the first and last recapture within a season [29]. We chose an index that averages movements over time rather than one that averages movements over number of recaptures because all individuals may not be captured during every trapping period [29]. We then calculated the mean AVDI from each site during each season.

We used a two factor analysis of variance (ANOVA) coupled with the Student-Neuman-Keuls (SNK) test to examine if differences in community (species richness, evenness, Shannon Diversity Index, abundance) and population response variables (cotton rat abundance, weight, percent juveniles, number of recaptures, movement) occurred among habitat types and seasons. The assumptions of normality and/or equal variance were not met for any community response variable and four of the population response variables (cotton rat abundance, weight, percent juveniles, number of recaptures). We rank transformed these eight response variables to conduct the two factor ANOVA. The use of rank transformation in conjunction with a parametric test is the equivalent of a nonparametric two factor ANOVA [30]. Additionally, some sites did not yield any cotton rat recaptures and resulted in missing values that prevented us from testing if an interaction effect occurred within the ANOVA analyses of mean number of recaptures and mean AVDI. ANOVA analyses were conducted using SigmaStat 3.1 for Windows [31] and a significance level of $\mathrm{P}<0.05$. Detrended correspondence analyses (DCA) were conducted on percentages of captures of small mammal species from each season to examine if species composition differed among habitat types in each season. To reduce the influence of rare species on the DCA results we omitted species that occurred in $<10 \%$ of all collections and selected the option in PC-ORD that results in downweighting of species that occurred $<$ the frequency of the most common species/5 (i.e., $<15$ to 20\%) [32]. DCA analyses were conducted using PC-ORD for Windows [32].

\section{Results}

\subsection{Community Responses}

Ten small mammal species from 1743 captures occurred within a total of 12,446 trap nights. The three most frequently captured small mammals in all habitat types were hispid cotton rat, woodland vole (Microtus pinetorum), and the marsh rice rat (Oryzomys palustris) (Table 3 ). Species richness, evenness, Shannon Diversity Index, and abundance differed $(\mathrm{P}<0.05)$ among habitat types (Table 4). Mean species richness was the greatest in Type II habitats and the least in Type IV habitats (Table 5). Mean evenness and abundance were the greatest in Type III habitats and the least in Type I habitats (Table 5). Mean Shannon Diversity Index within Type II, III, and IV habitats was greater than diversity within Type I habitats (Table 5). Species richness, Shannon Diversity Index, and abundance also differed $(\mathrm{P}<0.05)$ among seasons (Table 4). Mean species richness, Shannon Diversity Index, and abundance were the least in summer 1994, increased in the fall 1994, and then either declined in the spring 1995 (species richness), declined in the summer 1995 (Shannon Diversity Index), or did not decline during the remainder of the study (abundance) (Table 5). None of the community response variables exhibited a significant interaction effect of habitat type and season (Table 4). Species composition did not differ among habitat types due to the variability in small mammal species composition that occurred among sites within habitat types (Figure 2). Type I habitats exhibited greater within habitat variability in species composition than the other habitat types from summer 1994 to spring 1995 (Figure 2). Variability in species composition was reduced within all habitat types in the summer 1995 (Figure 2).

\subsection{Population Responses}

We captured 386 individual cotton rats within all habitat types, and we marked and released 200 cotton rats between summer 1994 and spring 1995. One hundred and twenty cotton rats were recaptured within the same site at least once during a season. Only 32 from a possible 184 
Table 3. Number of small mammal species captured within four restored riparian habitat types in northwestern Mississippi, June 1994 to July 1995.

\begin{tabular}{ccccc}
\hline Species & Type I & Type II & Type III & Type IV \\
\hline Hispid cotton rat (Sigmodon hispidus) & 77 & 273 & 209 & 320 \\
Woodland vole (Microtus pinetorum) & 1 & 37 & 115 & 64 \\
Marsh rice rat (Oryzomys palustris) & 2 & 38 & 96 & 52 \\
Cotton mouse (Peromyscus gossypinus) & 1 & 50 & 60 & 29 \\
White-footed mouse (Peromyscus leucopus) & 2 & 29 & 39 & 32 \\
House mouse (Mus musculus) & 23 & 23 & 34 & 19 \\
Southern short-tailed shrew (Blarina carolinensis) & 6 & 20 & 7 & 22 \\
Southeastern shrew (Sorex longirostris) & 0 & 10 & 4 & 5 \\
Least shrew (Cryptotis parva) & 2 & 0 & 3 & 1 \\
Golden mouse (Ochrotomys nuttalli) & & & \\
\hline
\end{tabular}

Table 4. $P$ values from two factor analysis of variance tests conducted to determine if small mammal community and population response variables differed among habitat type, season, or the interaction of habitat type and season. $P$ values $<0.05$ are bolded.

\begin{tabular}{cccc}
\hline & Habitat Type & Season & Interaction Effect \\
\hline Community & & & $\mathbf{0 . 8 4 8}$ \\
Species richness & $\mathbf{0 . 0 4 9}$ & $<\mathbf{0 . 0 0 1}$ & $\mathbf{0 . 6 8 4}$ \\
Evenness & $\mathbf{0 . 0 3 5}$ & 0.212 & $\mathbf{0 . 1 0 8}$ \\
Shannon diversity index & $<\mathbf{0 . 0 0 1}$ & $<\mathbf{0 . 0 0 1}$ & $\mathbf{0 . 2 0 9}$ \\
Abundance & $\mathbf{0 . 0 4 0}$ & $<\mathbf{0 . 0 0 1}$ & $\mathbf{0 . 1 7 5}$ \\
\hline Population (Cotton Rat) & & $<\mathbf{0 . 0 0 1}$ & 0.032 \\
Abundance & 0.071 & $<\mathbf{0 . 0 0 1}$ & $<0.001$ \\
Percent juveniles & 0.296 & $<\mathbf{0 . 0 0 1}$ & - \\
Weight & $<\mathbf{0 . 0 0 1}$ & 0.081 & - \\
Number of recaptures & 0.143 & 0.916 & \\
\hline Average distance moved & 0.080 & & \\
\hline
\end{tabular}

Table 5. Habitat and season factor means (SD) for small mammal species richness, evenness, Shannon Diversity Index (H'), and abundance in restored riparian habitats in northwestern Mississippi, June 1994 to July 1995.

\begin{tabular}{cccccc}
\hline Factor & Level & \multicolumn{1}{c}{ Richness } & \multicolumn{1}{c}{ Evenness } & \multicolumn{1}{c}{ H' $^{\prime}$} & Abundance \\
\hline Habitat Type & Type I & $0.07(0.09) \mathrm{AB}$ & $0.26(0.38) \mathrm{B}$ & $0.26(0.42) \mathrm{B}$ & $0.28(0.37) \mathrm{B}$ \\
& Type II & $0.06(0.04) \mathrm{A}$ & $0.49(0.28) \mathrm{AB}$ & $0.99(0.53) \mathrm{A}$ & $0.30(0.20) \mathrm{AB}$ \\
& Type III & $0.05(0.03) \mathrm{AB}$ & $0.59(0.23) \mathrm{A}$ & $1.09(0.51) \mathrm{A}$ & $0.32(0.18) \mathrm{A}$ \\
& Type IV & $0.04(0.02) \mathrm{B}$ & $0.44(0.29) \mathrm{AB}$ & $0.89(0.62) \mathrm{A}$ & $0.23(0.17) \mathrm{AB}$ \\
\hline Season & Summer 1994 & $0.02(0.02) \mathrm{C}$ & $0.31(0.43) \mathrm{A}$ & $0.30(0.45) \mathrm{B}$ & $0.06(0.06) \mathrm{B}$ \\
& Fall 1994 & $0.07(0.04) \mathrm{A}$ & $0.43(0.27) \mathrm{A}$ & $1.04(0.48) \mathrm{A}$ & $0.47(0.24) \mathrm{A}$ \\
& Winter 1994 & $0.08(0.05) \mathrm{A}$ & $0.57(0.20) \mathrm{A}$ & $1.19(0.50) \mathrm{A}$ & $0.35(0.20) \mathrm{A}$ \\
& Spring 1995 & $0.05(0.03) \mathrm{B}$ & $0.51(0.29) \mathrm{A}$ & $1.06(0.63) \mathrm{A}$ & $0.23(0.13) \mathrm{A}$ \\
& Summer 1995 & $0.06(0.08) \mathrm{B}$ & $0.40(0.31) \mathrm{A}$ & $0.44(0.40) \mathrm{B}$ & $0.30(0.30) \mathrm{A}$ \\
\hline
\end{tabular}

${ }^{\mathrm{a}}$ Different letters indicate differences $(\mathrm{P}<0.05)$ in ranked means among habitat type or season for each response variable.

individuals (accounting for known trap mortalities occurring within a season) were recaptured within the same site at least once between seasons. None of the seasonal recaptures occurred within Type I habitats, 12 seasonal recaptures occurred within Type II habitats, nine occurred within Type III habitats, and 10 occurred within Type IV habitats. Cotton rat abundance did not differ ( $\mathrm{P}$
$>0.05)$ among habitat types, but differed $(\mathrm{P}<0.05)$ among seasons (Table 4). Mean cotton rat abundance was the least in summer 1994, winter 1994, and spring 1995 and was the greatest in fall 1994 and summer 1995 (Figure 3). Percent juvenile cotton rats and weight exhibited a significant $(\mathrm{P}<0.05)$ interaction effect (Table 4) as trends in these response variables among habitat types 

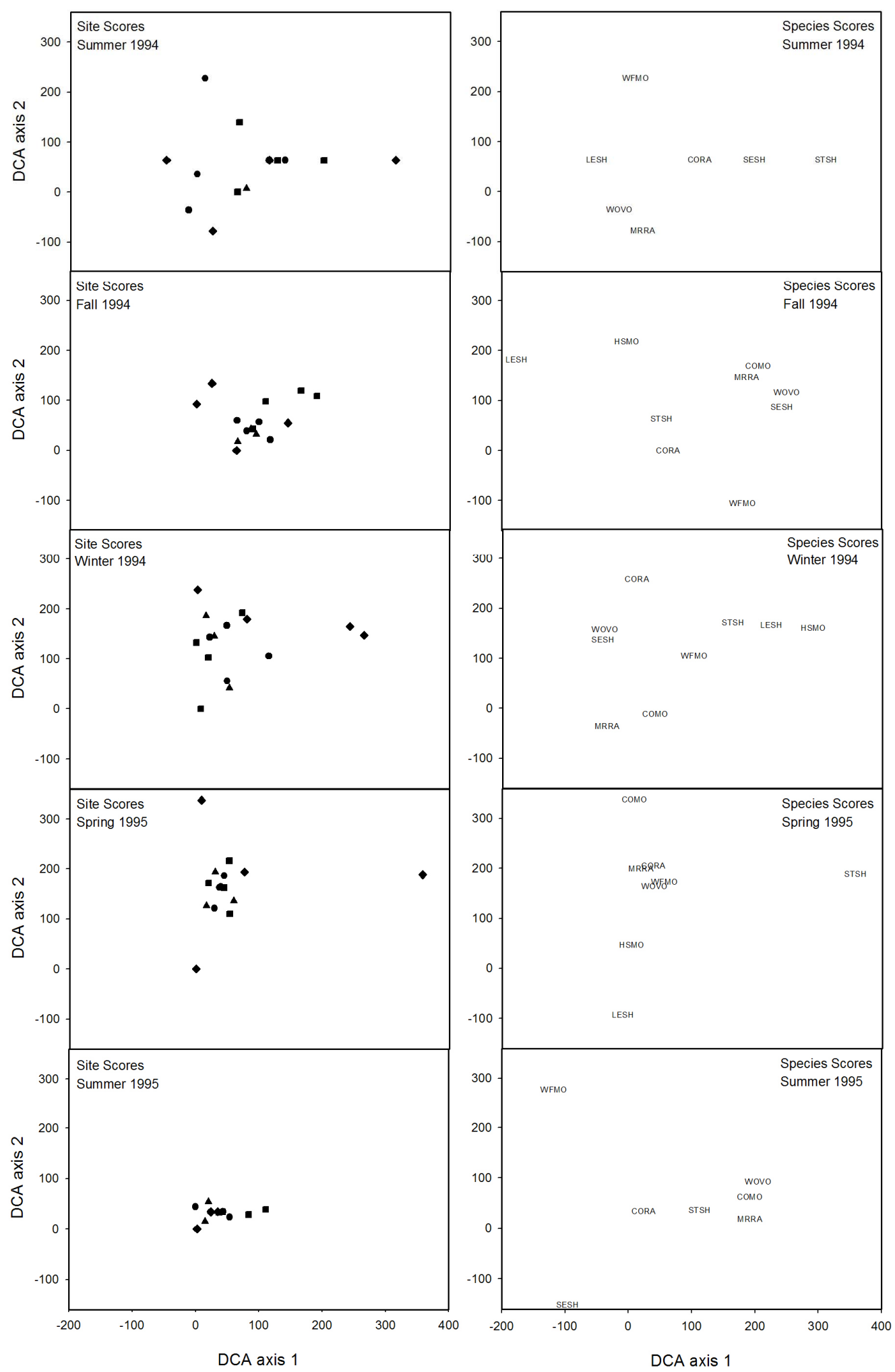

Figure 2. Site and species scores resulting from detrended correspondence analyses (DCA) of the percentage of small mammal species captured within four riparian habitat types in northwestern Mississippi during the summer 1994, fall 1994, winter 1994, spring 1995, and summer 1995. Habitat types are differentiated by different shapes within the figures: $\$:$ Type I sites; •: Type II sites; п: Type III sites; $\triangle$ : Type IV sites. Species codes are: COMO-cotton mouse; CORA-cotton rat; HSMO-house mouse; LESH-least shrew; MRRA-marsh rice rat; SESH-southeastern shrew; STSH-southern short-tailed shrew; WFMO-white-footed mouse; WOVO-woodland vole. 


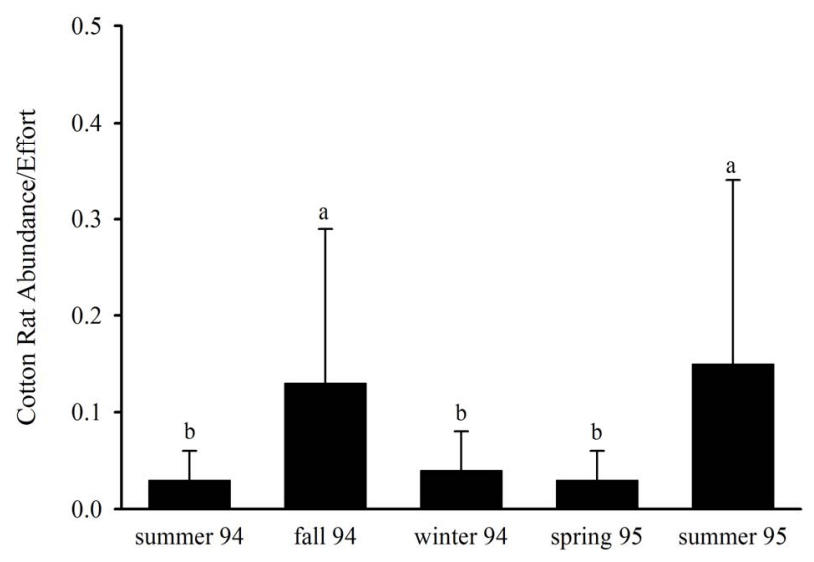

Figure 3. Mean cotton rat abundance within restored riparian habitats in northwestern Mississippi during summer 1994, fall 1994, winter 1994, spring 1995, and summer 1995.

differed among seasons. Mean percent juveniles did not differ among habitat types from summer 1994 to spring 1995 (Figure 4). Mean percent juveniles captured within Type I habitats was greater than the mean percent juveniles captured in the other three habitat types during summer 1995 (Figure 4). Mean cotton rat weight was greater in Type IV habitats than Type I, II, and III habitats during summer 1994 (Figure 5). No differences in mean cotton rat weight occurred among habitat types in fall 1994 (Figure 5). Mean weight was the least in Type I habitats, the greatest in Type II habitats, and intermediate in Type III and IV habitats in winter 1994 (Figure 5). Mean weight in Type II, III, and IV habitats was greater than mean weight in Type I habitats in spring and summer 1995 (Figure 5). Number of individuals recaptured and AVDI did not differ $(\mathrm{P}>0.05)$ among habitats or seasons (Table 3).

\section{Discussion}

\subsection{Community Responses}

Riparian habitats established by drop pipe installation contained nine small mammal species of the possible 16 native species present within the watersheds of our study sites [33] and only one non-native species (house mouse) was captured. Small mammal diversity within the southeastern United States is depauperate compared to other regions of the United States [34]. The levels of small mammal diversity and species composition we documented within these restored riparian habitats was similar to those found in other created agricultural wetlands [35], restored riparian zones [34], and managed pine forests [26,35-39] in the southeastern United States. Native small mammal species not captured within our study sites included eastern mole (Scalopus aquaticus), eastern chipmunk (Tamias striatus), eastern gray squirrel (Sciurus carolinensis), fox squirrel (Sciurus niger), southern fly- ing squirrel (Glaucomys volans), eastern harvest mouse (Reithrodontomys humulis), and the eastern woodrat ( $\mathrm{Ne}$ otoma floridana). Absence of these species from our study sites likely resulted from low capture vulnerability of these species to our trapping methods and/or their habitat preferences.

In general, Type II, III, and IV habitats exhibited greater species richness, evenness, diversity, and abundance than Type I habitats. We attribute these changes in community structure to the greater habitat area and vegetative structure within Type II, III, and IV habitats compared to Type I habitats. Small mammal communities within remnant habitats (i.e., riparian zones, shelter belts, etc.) in agricultural landscapes are primarily influenced by habitat area and vegetative structure [40]. Small mammal species richness and abundance within riparian zones of agricultural streams in Quebec increased with increasing riparian widths and increasing vegetative structure [41]. Species richness of all small mammals and those preferring woodland habitat increased with increasing habitat area within fragmented forested riparian habitats and woodlots in Illinois [42]. Small mammal species richness and diversity increased with increasing habitat area and structural diversity within hedgerows in agricultural fields on Prince Edward Island, Canada [43] and within shelterbelts in Minnesota [40].

However, we did not observe a consecutive increase in species richness, evenness, diversity, and abundance from Type II to Type IV habitats despite increases in habitat area and vegetative structure. We were surprised that Type IV habitats with the greatest habitat area and vegetative structure did not exhibit the greatest species richness, diversity, and abundance values. We suspect these results stem from the influence of increasing pool development (i.e., volume) that occurs from Type II to Type IV habitats. Little is known about the influence of increasing pool size on small mammal communities within riparian zones. Increased precipitation and flooding have been observed to decrease small mammal diversity and the abundance within riparian habitats in Mississippi and Missouri $[44,45]$. Increasing pool size within restored riparian habitats may also result in decreased small mammal diversity and abundance because it reduces the amount of terrestrial habitat within a site and the growth of herbaceous vegetation that is a critical habitat resource for many small mammals [45].

Seasonal changes in species richness, diversity, and species composition are likely a result of seasonal changes of cover and food resources within our sampling sites. We feel the seasonal changes in species richness and diversity were also influenced by the seasonal changes in cover and food resources within the adjacent agricultural fields. During the summer, crops present on the fields were approximately a meter tall, but little or no cover 

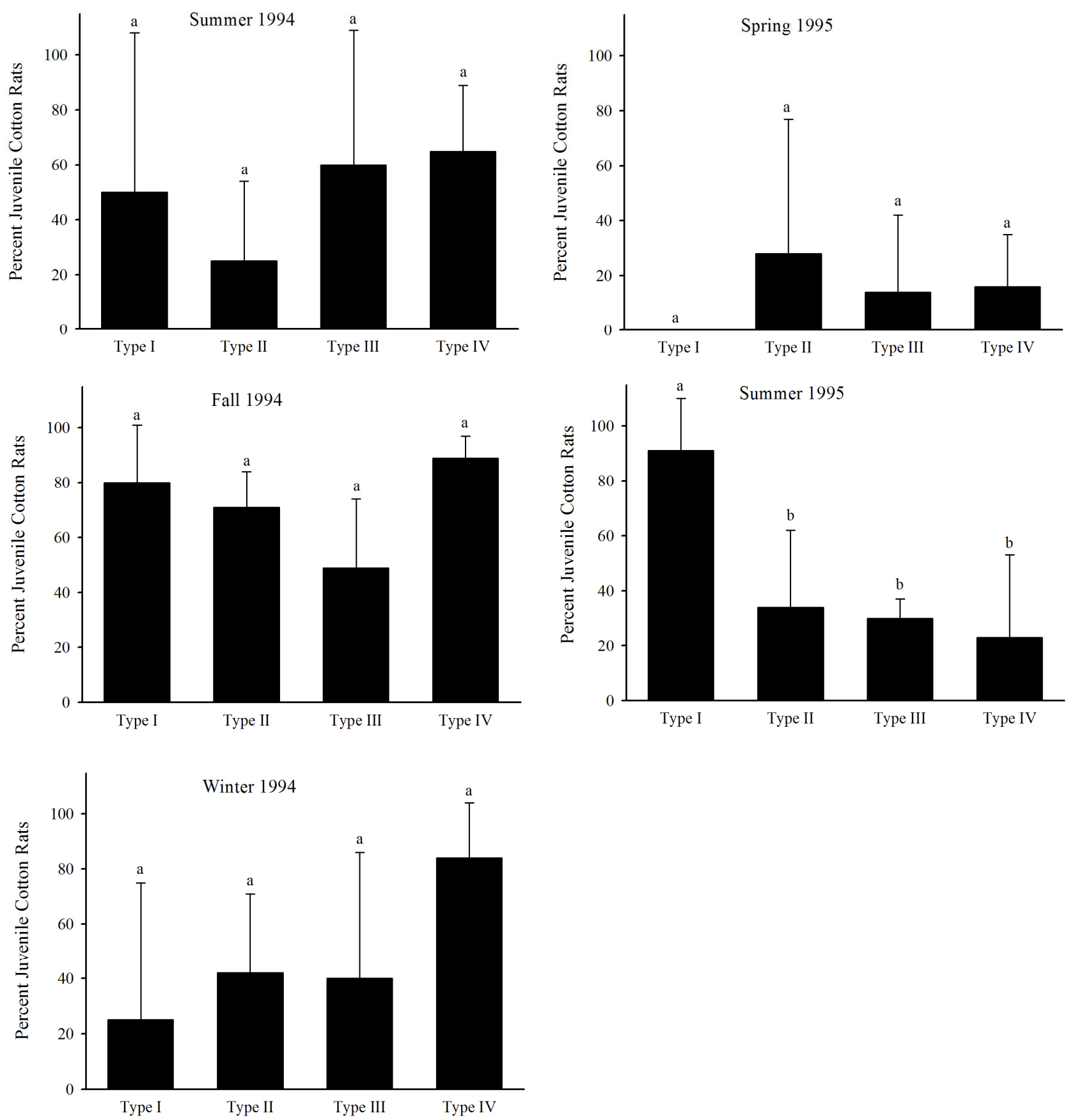

Figure 4. Mean percent juvenile cotton rats captured among four restored riparian habitat types in northwestern Mississippi during summer 1994, fall 1994, winter 1994, spring 1995, and summer 1995.

was present on the fields in the fall, winter, and spring. Therefore, observed declines in species richness and diversity during the summer may have occurred because small mammals were not limited to the riparian zone due to the increased cover and/or food resources available on agricultural fields.

\subsection{Population Responses}

Hispid cotton rats prefer grass dominated habitats, habi- tats with thick cover, and have been captured in vegetation areas adjacent to ponds [46,47]. Specifically, cotton rats prefer habitats having stands of dense grass species greater than $0.25 \mathrm{~m}$ high associated with various scrub species [46]. All habitats created by drop pipes met these general habitat criteria, which may explain the numerical dominance of cotton rats in all habitat types (Table 3). Cotton rat abundance, weight, and movement patterns were less within unpreferred habitats (mowed, minimal 

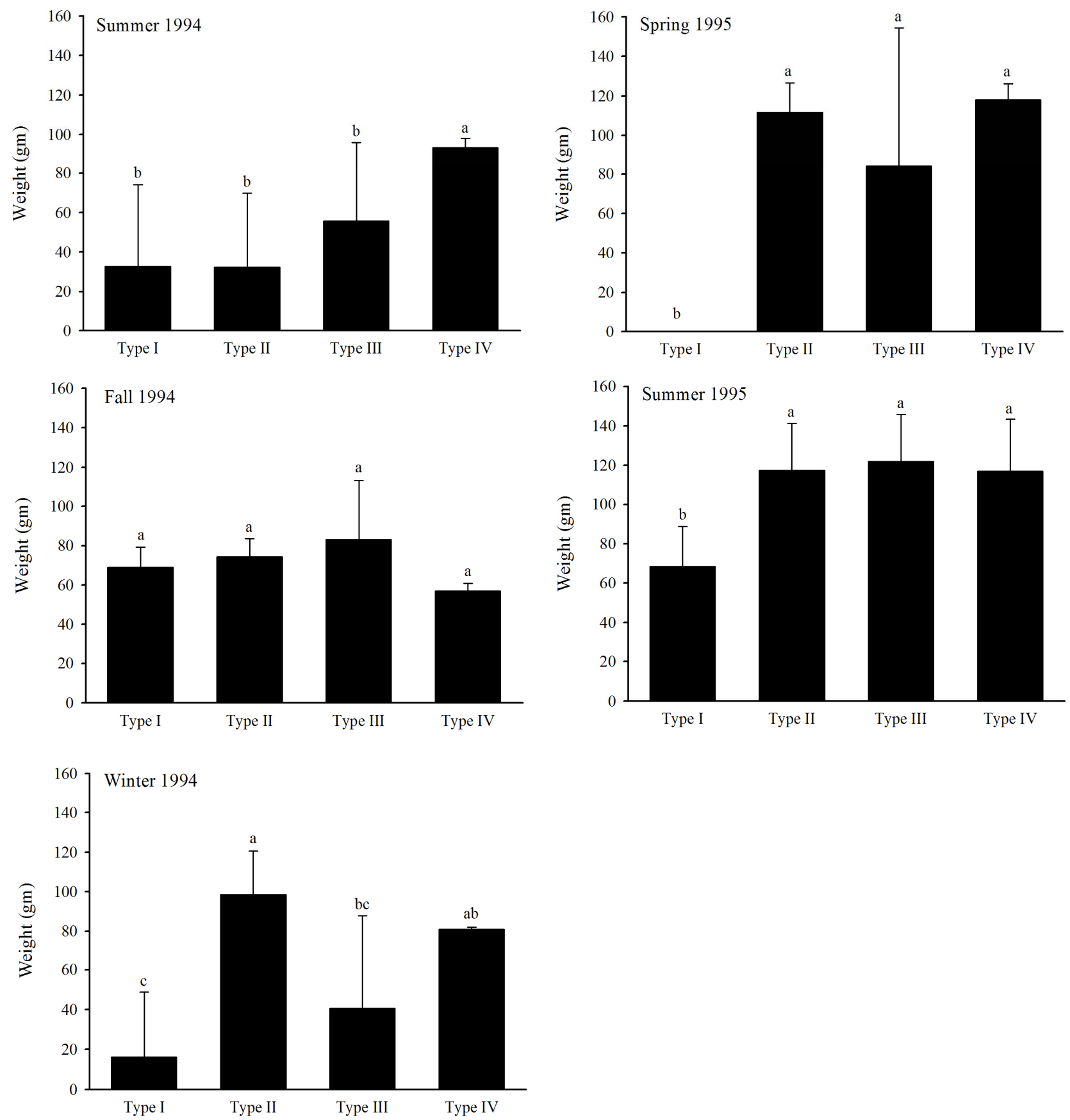

Figure 5. Mean cotton rat weight among four restored riparian habitat types in northwestern Mississippi during summer 1994, fall 1994, winter 1994, spring 1995, and summer 1995.

grass cover lacking shrub overstory) than preferred habitats (unmowed, dense grass cover with shrub overstory) in Texas coastal prairie [48]. Our results concur with these as we documented decreased cotton rat weights within small Type I habitats with reduced vegetative structure. We did not document differences in cotton rat abundance among restored riparian habitat types, but our results may have been obscured by gender differences as male and female cotton rats exhibit different habitat use patterns
$[49,50]$. We also documented greater percent of juvenile cotton rats in Type I habitats than the other three habitat types during summer 1995. Increased cotton rat abundance (adults and juveniles) also occurred during the summer 1995 and suggests the possibility that juvenile cotton rats were marginalized to the Type I habitats. Others in Oklahoma [46] and Georgia [49] have observed that smaller or juvenile cotton rats increase their usage of habitats with less cover during periods of increased 
cotton rat abundances.

\section{Conclusion}

Environmental problems associated with stream channelization and subsequent channel incision and gully erosion occur within agricultural watersheds throughout the world [51,52]. Our results provide insights on how a gully erosion control structure and similar water control structures used nationally and internationally can be used to assist with the restoration of riparian zones of channelized agricultural streams. We observed that small mammal diversity, abundance, and hispid cotton rat weight were the greatest in the riparian habitat types (Type II, III, IV) having greater habitat size, vegetative structural diversity, and pool size than the smallest riparian habitat types (Type I) with the least vegetative diversity. Present drop pipe installation practices focus on erosion control without consideration of riparian restoration. Our results indicate small mammals will benefit the most from the establishment of Type II, III, and IV habitats that are the habitat types least frequently created by drop pipe installlation. Modifying the drop pipe installation design to ensure that riparian habitats larger than $1000 \mathrm{~m}^{2}$ with pool volumes greater than $41 \mathrm{~m}^{3}$ and greater than $20 \%$ coverage of woody vegetation greater than $1.8 \mathrm{~m}$ tall are established within riparian zones adjacent to channelized agricultural streams in northwestern Mississippi will assist with the conservation of small mammals within these degraded riparian zones. Our findings also suggest that increasing the amount of terrestrial habitat associated with Type IV habitats containing large pools may promote increased diversity and abundance of small mammals. Future research on small mammals within riparian zones, agricultural fields, and other habitat types present within agricultural watersheds is necessary for developing watershed management plans that will benefit both wildlife and agriculture.

\section{Acknowledgements}

We thank the Vicksburg District US Army Corps of Engineers for providing partial cooperative funding and the USDA Natural Resources Conservation Service for landowner and site information. We also thank Eric Dibble, Norman Fausey, and Jeanne Jones for providing helpful comments on an earlier draft of this manuscript. Scott Knight and John Wigginton assisted with the start-up phase of this research. F. Douglas Shields Jr. provided data on the vegetative structure and assistance with analyzing the cotton rat movement data. Special appreciation goes to Chip Butts, Ezekiel Cooper, Kim Damon, Ken Kallies, Jonathan Maul, Todd Randall, Sam Testa, and John Wigginton for their assistance with field work.

\section{REFERENCES}

[1] R. J. Naiman, H. DeCamps and M. Pollock, "The Role of Riparian Corridors in Maintaining Regional Biodiversity," Ecological Applications, Vol. 3, No. 2, 1993, pp. 209-212. http://dx.doi.org/10.2307/1941822

[2] C. R. Hupp, "Riparian Vegetation, Channel Incision, and Ecogeomorphic Recovery," In: S. S. Y. Wang, E. J. Langendoen and F. D. Shields Jr., Eds., Management of Landscapes Disturbed by Channel Incision, Center for Computational Hydroscience and Engineering, University of Mississippi, University, Mississippi, 1997, pp. 3-11.

[3] S. C. Spackman and J. W. Hughes, "Assessment of Minimum Stream Corridor Width for Biological Conservation: Species Richness and Distribution Along Mid-order Streams in Vermont, USA," Biological Conservation, Vol. 71, 1995 , pp. 325-332.

http://dx.doi.org/10.1016/0006-3207(94)00055-U

[4] E. D. Fleharty and K. W. Navo, "Irrigated Cornfields as Habitat for Small Mammals in the Sandsage Prairie Region of Western Kansas," Journal of Mammalogy, Vol. 64, No. 3, 1983, pp. 367-379.

http://dx.doi.org/10.2307/1380349

[5] A. T. Doyle, "Use of Riparian and Upland Habitats by Small Mammals," Journal of Mammalogy, Vol. 71, No. 1, 1990, pp. 14-23. http://dx.doi.org/10.2307/1381312

[6] E. W. Chapman and C. A. Ribic., "The Impact of Buffer Strips and Stream-Side Grazing on Small Mammals in Southwestern Wisconsin," Agriculture, Ecosystems, and Environment, Vol. 88, No. 1, 2002, pp. 49-59. http://dx.doi.org/10.1016/S0167-8809(01)00154-2

[7] J. D. Osbourne, J. T. Anderson and A. B. Spurgeon, "Effects of Habitat on Small Mammal Diversity and Abundance in West Virginia," Wildlife Society Bulletin, Vol. 33, No. 3, 2005, pp. 814-822.

http://dx.doi.org/10.2193/0091-7648(2005)33[814:EOHO SD]2.0.CO;2

[8] S. C. Happ, G. Rittenhouse and G. C. Dobson, "Some Principles of Accelerated Stream and Valley Sedimentation," Technical Bulletin No. 695, United States Department of Agriculture, Washington DC, 1940.

[9] F. D. Shields Jr., S. S. Knight and C. M. Cooper, "Rehabilitation of Watersheds with Incising Channels," Water Resources Bulletin, Vol. 31, No. 6, 1995, pp. 971-982. http://dx.doi.org/10.1111/j.1752-1688.1995.tb03413.x

[10] R. Woodburn, "Science Studies a Gully," Soil Conservation, Vol. 15, No. 1, 1949, pp. 11-13, 22.

[11] E. H. Grissinger, J. B. Murphey and N. L. Coleman, "Planned Gully Research at the USDA National Sedimentation Laboratory," In: D. G. DeCoursey, Ed., Proceedings of the Natural Resources Modeling Symposium, USDA Agricultural Research Service, Publication ARS30, 1985, pp. 475-478.

[12] J. Poesen, J. Nachtergaele, G. Verstraeten and C. Valentin, "Gully Erosion and Environmental Change: Importance and Research Needs," Catena, Vol. 50, No. 2-4, 2003, pp. 91-133.

http://dx.doi.org/10.1016/S0341-8162(02)00143-1

[13] E. E. Possardt and W. E. Dodge, "Stream Channelization 
Impacts on Songbirds and Small Mammals in Vermont," Wildlife Society Bulletin, Vol. 6, No. 1, 1978, pp. 18-24.

[14] J. S. Barclay, "Impact of Stream Alterations on Riparian Communities in South-Central Oklahoma," Report \# FWS/OBS-80/17, Office of Biological Services, US Fish and Wildlife Service, Washington DC, 1980.

[15] T. T. Brown, T. L. Derting and K. Fairbanks, "The Effects of Stream Channelization and Restoration on Mammal Species and Habitat in Riparian Corridors," Journal of the Kentucky Academy of Sciences, Vol. 69, No. 1, 2008, pp. 37-49.

http://dx.doi.org/10.3101/1098-7096(2008)69[37:TEOSC A]2.0.CO;2

[16] A. R. Geier and L. B. Best, "Habitat Selection by Small Mammals of Riparian Communities: Evaluating Effects of Habitat Alterations," Journal of Wildlife Management, Vol. 44, No. 1, 1980, pp. 16-24.

http://dx.doi.org/10.2307/3808346

[17] F. D. Shields Jr., P. C. Smiley Jr. and C. M. Cooper, "Design and Management of Edge-of-field water Control Structures for Ecological Benefits," Journal of Soil and Water Conservation, Vol. 57, No. 3, 2002, pp. 151-157.

[18] F. D. Shields Jr., P. C. Smiley Jr. and C. M. Cooper, "Modifying Erosion Control Structures for Ecological Benefits," Journal of Soil and Water Conservation, Vol. 62, No. 6, 2007, p. 157A.

[19] C. M. Cooper, P. C. Smiley Jr., J. D. Wigginton, S. S. Knight and K. W. Kallies, "Vertebrate Use of Habitats Created by Installation of Field-scale Erosion Control Structures," Journal of Freshwater Ecology, Vol. 12, No. 2, 1997, pp. 199-207. http://dx.doi.org/10.1080/02705060.1997.9663527

[20] C. M. Cooper, F. D. Shields Jr., S. Testa III and S. S. Knight, "Sediment Retention and Water Quality Enhancement in Disturbed Watersheds," International Journal of Sediment Research, Vol. 15, No. 1, 2000, pp. 121-134.

[21] P. C. Smiley Jr., S. S. Knight, C. M. Cooper and K. W. Kallies, "Fish Richness and Abundance in Created Riparian Habitats of Channelized Northern Mississippi Streams," Southeastern Fishes Council Proceedings, Vol. 39, 1999, pp. 7-12.

[22] J. D. Maul, P. C. Smiley Jr. and C. M. Cooper, "Patterns of Avian Nest Predators and a Brood Parasite among Restored Riparian Habitats in Agricultural Watersheds," Environmental Monitoring and Assessment, Vol. 108, No. $1-3,2005$, pp. 133-150. http://dx.doi.org/10.1007/s10661-005-3962-9

[23] P. C. Smiley Jr., J. D. Maul and C. M. Cooper, "Avian Community Structure among Restored Riparian Habitats in Northwestern Mississippi," Agriculture, Ecosystems, and Environment, Vol. 122, No. 2, 2007, pp. 149-156. http://dx.doi.org/10.1016/j.agee.2006.12.028

[24] P. C. Smiley Jr., S. S. Knight, F. D. Shields Jr. and C. M. Cooper, "Influence of Gully Erosion Control on Amphibian and Reptile Communities within Riparian Zones of Channelized Streams," Ecohydrology, Vol. 2, No. 3, 2009, pp. 303-312. http://dx.doi.org/10.1002/eco.59

[25] P. C. Smiley Jr., C. M. Cooper, K. W. Kallies and S. S. Knight, "Assessing Habitats Created by Installation of
Drop Pipes," In: S. S. Y. Wang, E. J. Langendoen and F. D. Shields Jr., Eds., Management of Landscapes Disturbed by Channel Incision, Center for Computational Hydroscience and Engineering, University of Mississippi, University, Mississippi, 1997, pp. 887-892.

[26] D. A. Miller, R. E. Thill, M. A. Melchoirs, T. B. Wigley and P. A. Tappe, "Small Mammal Communities of Streamside Management Zones in Intensively Managed Pine Forests of Arkansas," Forest Ecology and Management, Vol. 203, No. 1-3, 2004, pp. 381-393. http://dx.doi.org/10.1016/j.foreco.2004.08.007

[27] B. Smith and J. B. Wilson, "A Consumer's Guide to Evenness Indices," Oikos, Vol. 76, No. 1, 1996, pp. 70-82. http://dx.doi.org/10.2307/3545749

[28] A. E. Magurran, "Ecological Diversity and its Measurement," Croom helm, London, 1988. http://dx.doi.org/10.1007/978-94-015-7358-0

[29] G. N. Cameron and W. B. Kincaid, "Species Removal Effects on Movements of Sigmodon hispidus and Reithrodontomys fulvescens," American Midland Naturalist, Vol. 108, No. 1, 1982, pp. 60-67. http://dx.doi.org/10.2307/2425292

[30] W. J. Conover, "Practical Nonparametric Statistics," John Wiley, New York, 1999.

[31] Systat Software, "SigmaStat 3.1 for Windows," Point Richmond, California, 2004.

[32] B. McCune and M. J. Mefford, "Multivariate Analysis of Ecological Data version 4.01. MjM Software," Gleneden Beach, Oregon, 1999.

[33] J. R. Choate, J. K. Jones Jr. and C. Jones, "Handbook of Mammals of the South-central States," Louisiana State University Press, Baton Rouge, Louisiana, 1994.

[34] L. D. Wike, F. D. Martin, H. G. Hanlin and L. S. Paddock, "Small Mammal Populations in a Restored Stream Corridor," Ecological Engineering, Vol. 15, No. S1, 2000, pp. S121-S129. http://dx.doi.org/10.1016/S0925-8574(99)00078-6

[35] T. A. Whitsitt and P. A. Tappe, "Temporal Variation of a Small-Mammal Community at a Wetland Restoration Site in Arkansas," Southeastern Naturalist, Vol. 8, 2009, pp. 381-386. http://dx.doi.org/10.1656/058.008.0301

[36] M. S. Mitchell, K. S. Karriker, E. J. Jones and R. A. Lancia, "Small Mammal Communities Associated with Pine Plantation Management of Pocosins," Journal of Wildlife Management, Vol. 49, No. 4, 1995, pp. 875-881. http://dx.doi.org/10.2307/3801969

[37] R. E. Masters, R. L. Lochmiller, S. T. McMurry and G. A. Bukenhofer, "Small Mammal Response to Pine-Grassland Restoration for Red-Cockaded Woodpeckers," Wildlife Society Bulletin, Vol. 26, No. 1, 1998, pp. 148-158.

[38] N. L. Constantine, T. A. Campbell, W. M. Baughman, T. B. Harrington, B. R. Chapman and K. V. Miller, "Effects of Clearcutting with Corridor Retention on Abundance, Richness, and Diversity of Small Mammals in the Coastal Plain of South Carolina, USA," Forest Ecology and Management, Vol. 202, No. 1-3, 2004, pp. 293-300. http://dx.doi.org/10.1016/j.foreco.2004.07.036

[39] R. W. Perry and R. E. Thill, "Small Mammal Responses 
to Pine Regeneration Treatments in the Ouachita Mountains of Arkansas and Oklahoma, USA," Forest Ecology and Management, Vol. 219, No. 1, 2005, pp. 81-94. http://dx.doi.org/10.1016/j.foreco.2005.09.001

[40] R. H. Yahner, "Small Mammals in Farmstead Shelterbelts: Habitat Correlates of Seasonal Abundance and Community Structure," Journal of Wildlife Management, Vol. 47, No. 1, 1983, pp. 74-84. http://dx.doi.org/10.2307/3808054

[41] C. Maisonneuve and S. Rioux, "Importance of Riparian Habitats for Small Mammal and Herpetofaunal Communities in Agricultural Landscapes of Southern Quebec," Agriculture, Ecosystems and Environment, Vol. 83, No. $1-2,2001$, pp. 165-175. http://dx.doi.org/10.1016/S0167-8809(00)00259-0

[42] D. L. Rosenblatt, E. J. Heske, S. L. Nelson, D. M. Barber, M. A. Miller and B. MacAllister, "Forest Fragments in East-central Illinois: Islands or Habitat Patches for Mammals?" American Midland Naturalist, Vol. 141, No. 1, 1999, pp. 115-123.

http://dx.doi.org/10.1674/0003-0031(1999)141[0115:FFI $\mathrm{ECI}] 2.0 . \mathrm{CO} ; 2$

[43] M. Silva and M. E. Prince, "The Conservation Value of Hedgerows for Small Mammals in Prince Edward Island, Canada," American Midland Naturalist, Vol. 159, No. 1, 2008, pp. 110-124.

http://dx.doi.org/10.1674/0003-0031(2008)159[110:TCV OHF]2.0.CO;2

[44] M. J. Chamberlain and B. D. Leopold, "Effects of a Flood on Relative Abundance and Diversity of Small Mammals in a Regenerating Bottomland Hardwood Forest," Southwestern Naturalist, Vol. 48, No. 2, 2003, pp. 306-309. http://dx.doi.org/10.1894/0038-4909(2003)048<0306:EO AFOR $>2.0 . \mathrm{CO} ; 2$
[45] A. G. Elliott and B. G. Root, "Small Mammal Responses to Silvicultural and Precipitation-Related Disturbances in Northeastern Missouri Riparian Forests," Wildlife Society Bulletin, Vol. 34, No. 2, 2006, pp. 485-601. http://dx.doi.org/10.2193/0091-7648(2006)34[485:SMRT $\mathrm{SA}\rceil 2.0 . \mathrm{CO} ; 2$

[46] J. W. Goertz, "The Influence of Habitat Quality upon the Density of Cotton Rat Populations," Ecological Monographs, Vol. 34, No. 4, 1964, pp. 359-381. http://dx.doi.org/10.2307/2937068

[47] G. N. Cameron and S. R. Spencer, "Sigmodon hispidus," Mammalian Species, Vol. 158, 1981, pp. 1-9. http://dx.doi.org/10.2307/3504057

[48] S. R. Spencer and G. N. Cameron, "Behavioral Dominance and Its Relationship to Habitat Patch Utilization by the Hispid Cotton Rat (Sigmodon hispidus)," Behavioral Ecology and Sociobiology, Vol. 13, No. 1, 1983, pp. $27-$ 36. http://dx.doi.org/10.1007/BF00295073

[49] W. Z. Lidicker, J. O. Wolff, L. N. Lidicker and M. H. Smith, "Utilization of a Habitat Mosaic by Cotton Rats During a Population Decline," Landscape Ecology, Vol. 6, No. 4, 1992, pp. 259-268. http://dx.doi.org/10.1007/BF00129704

[50] G. N. Cameron and W. B. Kincaid, "Mechanisms of Habitat Selection by the Hispid Cotton Rat (Sigmodon hispidus)," Journal of Mammalogy, Vol. 89, No. 1, 2008, pp. 126-131. http://dx.doi.org/10.1644/07-MAMM-A-092.1

[51] A. Brookes, "Channelized Rivers: Perspectives for Environmental Management," Wiley, Chichester, 1988.

[52] S. Y. Wang, E. J. Langendoen and F. D. Shields, "Management of Landscapes Disturbed by Channel Incision," Center for Computational Hydroscience and Engineering, University of Mississippi, Mississippi, 1997. 